\title{
The upward trend in the immunotherapy utilization for hepatobiliary cancers
}

\author{
Xiao-Bu Lan ${ }^{1}$, George Papatheodoridis ${ }^{2}$, Yu-Xian Teng ${ }^{3}$, Jian-Hong Zhong ${ }^{3}$ \\ ${ }^{1}$ Department of Pharmacy, The Fifth Affiliated Hospital of Guangxi Medical University, Nanning, China; ${ }^{2}$ Department of Gastroenterology, Medical \\ School of National and Kapodistrian University of Athens, General Hospital of Athens "Laiko", Athens, Greece; ${ }^{3}$ Department of Hepatobiliary \\ Surgery, Guangxi Liver Cancer Diagnosis and Treatment Engineering and Technology Research Center, Guangxi Medical University Cancer \\ Hospital, Nanning, China \\ Correspondence to: Jian-Hong Zhong. Guangxi Medical University Cancer Hospital, He Di Rd. 71, Nanning 530021, China. \\ Email: zhongjianhong@gxmu.edu.cn. \\ Comment on: Sahara K, Farooq SA, Tsilimigras DI, et al. Immunotherapy utilization for hepatobiliary cancer in the United States: disparities among \\ patients with different socioeconomic status. Hepatobiliary Surg Nutr 2020;9:13-24.
}

Submitted Aug 23, 2021. Accepted for publication Sep 09, 2021.

doi: $10.21037 / \mathrm{hbsn}-21-342$

View this article at: https://dx.doi.org/10.21037/hbsn-21-342

Hepatobiliary cancers (HBCs) include those of the liver [mainly hepatocellular carcinoma (HCC) and intrahepatic cholangiocarcinoma] and biliary tract (extrahepatic cholangiocarcinoma and gallbladder cancer). Based on the 2020 global cancer statistics, liver cancer ranks seventh in incidence and third in mortality among all malignant tumors, while gallbladder cancer ranks $25^{\text {th }}$ in incidence and $21^{\text {st }}$ in mortality (1). Due to the lack of typical symptoms and signs at the early stages, HBCs are often diagnosed at intermediate or advanced stages, and thus the opportunity of curative surgical interventions is missed (2). Therefore, most patients with $\mathrm{HBC}$ can only be treated with noncurative treatments, including immunotherapy. Several immunotherapeutic approaches have been attempted for HBCs, including oncolytic viruses, tumor vaccines, adoptive immunotherapy, and immune checkpoint inhibitors (ICIs; Figure 1). Of them, only ICIs, a promising group of agents that have been used in several malignancies in the past decade, have been used in clinical practice to prolong survival, and thus represent a new era in the treatment of HBCs. ICIs disrupt the tumor's immune tolerance, causing reactivation of the host's immune system against the cancer cells. Common ICIs include inhibitors of programmed cell death protein-1 (PD-1), programmed cell death ligand 1 (PD-L1), and cytotoxic T-lymphocyte-associated antigen-4 (CTLA-4). The use of immunotherapy may vary widely among different parts of the world and even among patient subgroups in the same country or area.

In one study, Sahara et al. (3) used the National Cancer Database to investigate the use of immunotherapy for HBC as well as factors affecting such use in USA. The most important finding was that the overall use of immunotherapy in US patients with HBCs was rather low but increased over time, while HCC, especially at the advanced stage, was the most frequent indication for the use of immunotherapy (3). These findings reflect the recent developments in immunotherapy for the management of HBCs. In 2017, based on the results of the CheckMate040 trial, the US Food and Drug Administration (FDA) approved the first ICI, nivolumab, as a second-line treatment option for patients with advanced or metastatic HCC (4). Following this, several trials were conducted that assessed the safety and efficacy of ICIs, given with or without tyrosine kinase inhibitors, as firstline (e.g., lenvatinib plus pembrolizumab, atezolizumab plus bevacizumab, sintilimab plus bevacizumab) or second-line therapy (e.g., pembrolizumab, nivolumab plus ipilimumab) in patients with advanced HCC (Table 1) (5-8). Further trials and retrospective studies have evaluated the efficacy of ICIs in patients with advanced HCC $(9,10)$. Currently, several ICIs have been approved by the FDA and included in the scientific guidelines, and their clinical use is being expanded to patients with HCC.

The more frequent use of immunotherapy in patients 


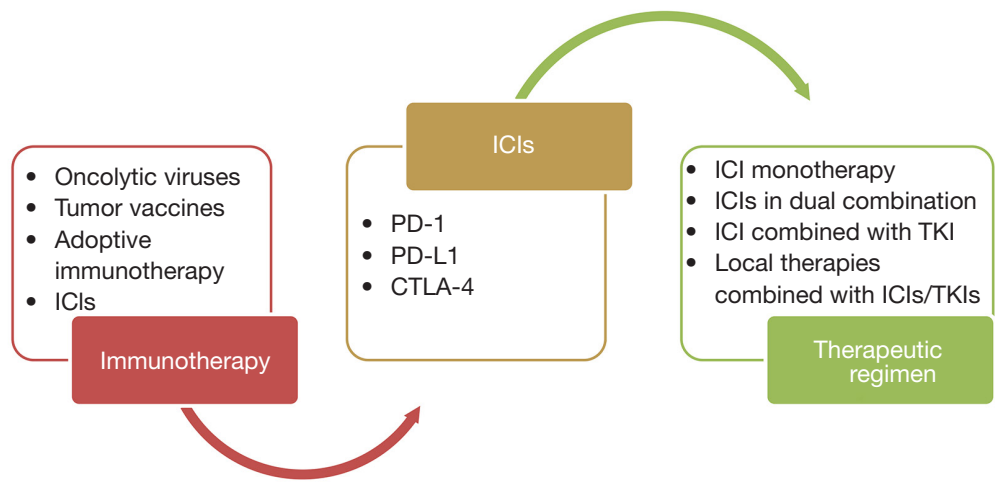

Figure 1 ICIs are the main immunotherapy drug for hepatobiliary cancer. CTLA-4, cytotoxic T lymphocyte-associated antigen-4; ICI, immune checkpoint inhibitor; PD-1, programmed cell death protein-1; PD-L1, programmed cell death ligand 1; TKI, tyrosine kinase inhibitor.

Table 1 Summary of data from published trials of immune checkpoint inhibitors in hepatocellular carcinoma

\begin{tabular}{|c|c|c|c|c|c|c|c|c|}
\hline Trials & Treatment and sample size & Phase & $\begin{array}{l}\text { ORR } \\
\text { according to } \\
\text { RECIST } 1.1, \%\end{array}$ & $\begin{array}{l}\text { Median } \\
\text { PFS time, } \\
\text { months }\end{array}$ & $\begin{array}{l}\mathrm{HR} \\
(95 \% \mathrm{Cl}) \\
\text { of PFS }\end{array}$ & $\begin{array}{l}\text { Median } \\
\text { survival time, } \\
\text { months }\end{array}$ & $\begin{array}{l}\mathrm{HR} \\
(95 \% \mathrm{Cl}) \\
\text { of OS }\end{array}$ & PMID \\
\hline $\begin{array}{l}\text { CheckMate } \\
040\end{array}$ & $\begin{array}{l}\text { Nivolumab dose-expansion }(n=214) \text { vs. } \\
\text { dose-escalation phase }(n=48)\end{array}$ & $\mathrm{I} / \mathrm{II}$ & 19.6 vs. 14.6 & 4.0 vs. 3.4 & - & $\begin{array}{l}\text { Not reached } \\
\text { vs. } 15\end{array}$ & - & 28434648 \\
\hline GO30140 & $\begin{array}{l}\text { Atezolizumab plus bevacizumab }(n=104) \\
\text { vs. atezolizumab plus bevacizumab } \\
(n=60) \text { vs. atezolizumab }(n=59)\end{array}$ & $\mathrm{lb}$ & $\begin{array}{l}32.7 \text { vs. } 13.3 \\
\quad \text { vs. } 8.5\end{array}$ & $\begin{array}{l}7.4 \text { vs. } 5.7 \\
\text { vs. } 2.0\end{array}$ & - & $\begin{array}{l}17.1 \text { vs. not } \\
\text { reached } v s . \\
\text { not reached }\end{array}$ & - & 32502443 \\
\hline RESCUE & Camrelizumab plus apatinib $(n=70)$ & II & 46.0 & 5.7 & - & 20.1 & - & 33087333 \\
\hline $\begin{array}{l}\text { CheckMate } \\
459\end{array}$ & Nivolumab $(n=371)$ vs. sorafenib $(n=372)$ & III & 15.4 vs. 7.0 & 3.7 vs. 3.8 & - & 16.4 vs. 14.7 & $\begin{array}{c}0.85 \\
(0.72-1.02)\end{array}$ & - \\
\hline ORIENT-32 & $\begin{array}{l}\text { Sintilimab plus bevacizumab }(n=380) \\
\text { vs. sorafenib }(n=191)\end{array}$ & III & 19.6 vs. 2.9 & 4.6 vs. 2.8 & $\begin{array}{c}0.56 \\
(0.46-0.70)\end{array}$ & $15^{\star}$ vs. 10.4 & $\begin{array}{c}0.57 \\
(0.43-0.75)\end{array}$ & 34143971 \\
\hline \multicolumn{9}{|l|}{ Second-line } \\
\hline $\begin{array}{l}\text { CheckMate } \\
040\end{array}$ & $\begin{array}{l}\text { Nivolumab plus ipilimumab (group } A \text {, } \\
n=50 \text {; group } B, n=49 \text {; group } C, n=49 \text { ) }\end{array}$ & $\mathrm{I} / \mathrm{II}$ & $\begin{array}{l}32.0 \text { vs. } 26.5 \\
\text { vs. } 28.6\end{array}$ & - & - & $\begin{array}{l}22.8 \text { vs. } 12.5 \\
\text { vs. } 12.7\end{array}$ & - & 33001135 \\
\hline RESCUE & Camrelizumab plus apatinib $(n=120)$ & II & 25 & 5.5 & - & 21.8 & - & 33087333 \\
\hline KEYNOTE-224 & Pembrolizumab $(n=104)$ & II & 17.3 & 4.9 & - & 12.9 & - & 29875066 \\
\hline KEYNOTE-240 & $\begin{array}{l}\text { Pembrolizumab ( } n=278) \text { vs. placebo } \\
(n=135)\end{array}$ & III & 18.3 vs. 4.4 & 3.0 vs. 2.8 & $\begin{array}{c}0.72 \\
(0.57-0.90)\end{array}$ & 13.9 vs. 10.6 & $\begin{array}{c}0.78 \\
(0.61-0.99)\end{array}$ & 31790344 \\
\hline
\end{tabular}

*, estimated from Kaplan-Meier survival curve. Cl, confidence interval; HCC, hepatocellular carcinoma; HR, hazard ratio; ORR, objective response rate; OS, overall survival; PFS, progression-free survival. 
with HCC and subsequent cholangiocarcinoma reflects the higher incidence of these cancers compared to gall bladder cancer. HCC is therefore more attractive for the development of clinical trials and thus more conducive to the clinical application of new therapies including immunotherapy. Cholangiocarcinoma is a less frequent cancer compared to HCC, but ICIs have also been explored in this highly heterogeneous malignancy, offering varying rates of efficacy. Notable results have only been observed with pembrolizumab for patients with cholangiocarcinoma and microsatellite instability-high or mismatch repairdeficient status (11). No trial of ICIs in the treatment of patients with gallbladder cancer has been reported to date, which explains the minimal use of immunotherapy in this setting.

Another interesting finding of the Sahara et al. (3) study was the independent association of socioeconomic factors, particularly of patients' median income, with the probability of using immunotherapy. These types of associations can be expected in expensive treatment options, especially in countries without total national health coverage for the population. Similar associations between the patients' income and the likelihood of immunotherapy use have been reported in US patients with other malignancies (12). In general, patients in the advanced stages of any cancer and with high income are more likely to receive new, expensive therapeutic regimens, such as immunotherapy, for several reasons that include the affordability of the treatment cost and the greater frequency of management by experts disposed to using novel agents. The increasing popularity and use of ICIs over time are expected to gradually reduce the disparity in access to immunotherapy of patients of different socioeconomic status.

The third finding of the study by Sahara et al. (3) was the independent association of immunotherapy use with more frequent prior receipt of cytotoxic chemotherapy. Although the details concerning cytotoxic chemotherapy were not provided, it is anticipated that the more difficult-to-treat patients with $\mathrm{HBC}$ who have received several pre-existing treatment options will be the candidates and will eventually be treated with immunotherapy. The safety and efficacy of several combinations of ICIs with other type of agents or locoregional therapies in patients with HBCs are currently being investigated in phase II and phase III trials.

Although immunotherapy has revolutionized the treatment of HBCs over the last decade and its indications are constantly expanding, the identification of patients who will receive the best survival benefit and of those biomarkers that could drive personalized treatment decisions are lacking. A recent meta-analysis of 3 randomized trials (CheckMate 459, KEYNOTE-240, IMbrave150) suggested that ICI-inclusive regimens do not improve the survival of patients with nonviral HCC (13). This finding was confirmed in 2 additional cohorts of patients with nonalcoholic steatohepatitis-related HCC who had reduced overall survival after ICI therapy compared to patients with HCC related to other etiologies (13). The better stratification of patients with $\mathrm{HBCs}$ in relation to their response to immunotherapy and the identification of reliable biomarkers for a personalized approach could lead to more frequent and more effective use of such innovative treatment options for HBCs.

\section{Acknowledgments}

Funding: This work was supported by the National Natural Science Foundation of China (no. 82060510), "Guangxi BaGui Scholars" Special Fund (no. 2019AQ20), and the Natural Science Foundation of Guangxi Province (no. 2020GXNSFAA159022).

\section{Footnote}

Provenance and Peer Review: This article was commissioned by the editorial office of Hepatobiliary Surgery and Nutrition. The article did not undergo external peer review.

Conflicts of Interest: All authors have completed the ICMJE uniform disclosure form (available at https://hbsn. amegroups.com/article/view/10.21037/hbsn-21-342/coif). Dr. GP has served as lecturer/advisor for Bayern, Ipsen, and Roche. The other authors have no conflicts of interest to declare.

Ethical Statement: The authors are accountable for all aspects of the work in ensuring that questions related to the accuracy or integrity of any part of the work are appropriately investigated and resolved.

Open Access Statement: This is an Open Access article distributed in accordance with the Creative Commons Attribution-NonCommercial-NoDerivs 4.0 International License (CC BY-NC-ND 4.0), which permits the noncommercial replication and distribution of the article with the strict proviso that no changes or edits are made and the original work is properly cited (including links to both the 
formal publication through the relevant DOI and the license). See: https://creativecommons.org/licenses/by-nc-nd/4.0/.

\section{References}

1. Sung H, Ferlay J, Siegel RL, et al. Global Cancer Statistics 2020: GLOBOCAN Estimates of Incidence and Mortality Worldwide for 36 Cancers in 185 Countries. CA Cancer J Clin 2021;71:209-49.

2. Zhong JH, Peng NF, You XM, et al. Tumor stage and primary treatment of hepatocellular carcinoma at a large tertiary hospital in China: A real-world study. Oncotarget 2017;8:18296-302.

3. Sahara K, Farooq SA, Tsilimigras DI, et al. Immunotherapy utilization for hepatobiliary cancer in the United States: disparities among patients with different socioeconomic status. Hepatobiliary Surg Nutr 2020;9:13-24.

4. El-Khoueiry AB, Sangro B, Yau T, et al. Nivolumab in patients with advanced hepatocellular carcinoma (CheckMate 040): an open-label, non-comparative, phase $1 / 2$ dose escalation and expansion trial. Lancet 2017;389:2492-502.

5. Finn RS, Ikeda M, Zhu AX, et al. Phase Ib Study of Lenvatinib Plus Pembrolizumab in Patients With Unresectable Hepatocellular Carcinoma. J Clin Oncol 2020;38:2960-70.

6. Finn RS, Qin S, Ikeda M, et al. Atezolizumab plus Bevacizumab in Unresectable Hepatocellular Carcinoma.
N Engl J Med 2020;382:1894-905.

7. Ren $Z, X u J$, Bai $Y$, et al. Sintilimab plus a bevacizumab biosimilar (IBI305) versus sorafenib in unresectable hepatocellular carcinoma (ORIENT-32): a randomised, open-label, phase 2-3 study. Lancet Oncol 2021;22:977-90.

8. Finn RS, Ryoo BY, Merle P, et al. Pembrolizumab As Second-Line Therapy in Patients With Advanced Hepatocellular Carcinoma in KEYNOTE-240: A Randomized, Double-Blind, Phase III Trial. J Clin Oncol 2020;38:193-202.

9. Deng ZJ, Li L, Teng YX, et al. Treatments of Hepatocellular Carcinoma with Portal Vein Tumor Thrombus: Current Status and Controversy. J Clin Transl Hepatol 2021. doi: 10.14218/JCTH.12021.00179.

10. Zhang T, Merle P, Wang H, et al. Combination therapy for advanced hepatocellular carcinoma: do we see the light at the end of the tunnel? Hepatobiliary Surg Nutr 2021;10:180-92.

11. Charalampakis N, Papageorgiou G, Tsakatikas S, et al. Immunotherapy for cholangiocarcinoma: a 2021 update. Immunotherapy 2021;13:1113-34.

12. Al-Qurayshi Z, Crowther JE, Hamner JB, et al. Disparities of Immunotherapy Utilization in Patients with Stage III Cutaneous Melanoma: A National Perspective. Anticancer Res 2018;38:2897-901.

13. Pfister D, Núñez NG, Pinyol R, et al. NASH limits antitumour surveillance in immunotherapy-treated HCC. Nature 2021;592:450-6.

Cite this article as: Lan XB, Papatheodoridis G, Teng YX, Zhong JH. The upward trend in the immunotherapy utilization for hepatobiliary cancers. HepatoBiliary Surg Nutr 2021;10(5):692-695. doi: 10.21037/hbsn-21-342 